\title{
Simulation of the Influence of Pulsed Magnetic Field on the Superalloy Melt with the Solid-Liquid Interface in Directional Solidification
}

\author{
Kuiliang Zhang ${ }^{1,2} \cdot$ Yingju Li $^{1,2} \cdot$ Yuansheng Yang ${ }^{1,2}$ \\ Received: 20 December 2019 / Revised: 9 March 2020 / Published online: 29 April 2020 \\ (c) The Chinese Society for Metals (CSM) and Springer-Verlag GmbH Germany, part of Springer Nature 2020
}

\begin{abstract}
The effect of the pulsed magnetic field on the grain refinement of superalloy K4169 has been studied in directional solidification. In the presence of the solid-liquid interface condition, the distributions of the electromagnetic force, flow field, temperature field, and Joule heat in front of the solid-liquid interface in directional solidification with the pulsed magnetic field are simulated. The calculation results show that the largest electromagnetic force in the melt appears near the solidliquid interface, and the electromagnetic force is distributed in a gradient. There are intensive electromagnetic vibrations in front of the solid-liquid interface. The forced melt convection is mainly concentrated in front of the solid-liquid interface, accompanied by a larger flow velocity. The simulation results indicate that the grain refinement is attributed to that the electromagnetic vibration and forced convection increase the nucleation rate and the probability of dendrite fragments survival, for making dendrite easily fragmented, homogenizing the melt temperature, and increasing the undercooling in front of the solid-liquid interface.
\end{abstract}

Keywords Pulsed magnetic field $\cdot$ Solid-liquid interface $\cdot$ Simulation $\cdot$ Electromagnetic force $\cdot$ Melt convection Superalloy

\section{List of Symbols}

B Magnetic flux density vector, $\mathrm{T}$

$C_{p} \quad$ Specific heat, $\mathrm{J} /(\mathrm{kg} \cdot \mathrm{K})$

$D$ Electric flux density vector, $\mathrm{C} / \mathrm{m}^{2}$

$\boldsymbol{E}$ Electric field density vector, $\mathrm{V} / \mathrm{m}$

$f \quad$ Electromagnetic force, $\mathrm{N}$

$\boldsymbol{H}$ Magnetic field intensity vector, $\mathrm{A} / \mathrm{m}$

$\boldsymbol{J}$ Total current density vector, $\mathrm{A} / \mathrm{m}^{2}$

$k$ Thermal conductivity, $\mathrm{W} /(\mathrm{m} \cdot \mathrm{K})$

$p$ Pressure, $\mathrm{Pa}$

$Q_{\mathrm{V}} \quad$ Volumetric heat source, $\mathrm{J} /\left(\mathrm{m}^{3} \cdot \mathrm{s}\right)$

$t \quad$ Time, $\mathrm{s}$

$T$ Temperature, $\mathrm{K}$

$\boldsymbol{v}$ Velocity vector, $\mathrm{m} / \mathrm{s}$

$\rho \quad$ Electric charge density, $\mathrm{C} / \mathrm{m}^{3}$

$\sigma \quad$ Conductivity, $1 /(\Omega \cdot \mathrm{m})$

Available online at https://link.springer.com/journal/40195.

Yuansheng Yang

ysyang@imr.ac.cn

1 Institute of Metal Research, Chinese Academy of Sciences, Shenyang 110016, China

2 School of Materials Science and Engineering, University of Science and Technology of China, Hefei 230026, China $\mu_{0} \quad$ Magnetic permeability, $\mathrm{H} / \mathrm{m}$

$\mu \quad$ Dynamic viscosity, $\mathrm{Pa} \cdot \mathrm{s}$

\section{Introduction}

Grain refinement plays an important role in enhancing the mechanical properties of equiaxed superalloy castings at a moderate temperature. Recently, the pulsed magnetic field (PMF) has been regarded as an effective method for grain refinement. The solidification microstructures of superalloy [1], steel [2], aluminum alloy [3, 4], and magnesium alloy $[5,6]$ can be significantly refined by the PMF. The PMF is easier to be controlled and higher in instantaneous energy than other magnetic fields, so it has been considered as a promising approach for grain refinement of metallic materials. Because it is difficult to observe the changes of the electromagnetic force and flow field distributions generated by the PMF in metallic melt, the numerical simulation calculation is used to reveal the influences of the PMF. Kolesnichenko et al. [7] simulated the electromagnetic force produced by sine wave current and its flow distributions under the PMF. It is found that the direction of the electromagnetic force changes periodically in the melt, and two flow patterns remain identical with the action of the 
electromagnetic force during the whole period. Wang et al. [8] studied the flow field caused by the PMF in magnesium alloy melt in one pulse period. They proposed that the melt convection and melt vibration are the main reasons for grain refinement. Ma et al. [9] investigated the distributions of the electromagnetic force, flow field, and Joule heat in superalloy melt with the action of the PMF. The melt vibration makes it easier for heterogeneous nuclei to be dissociated from the wall of the mold and the melt convection causes nuclei to be separated into the melt [10]. Teng et al. [11] simulated the distributions of the flow field and Joule heat in the superalloy melt under a continuous pulse PMF. They found that the distribution of the flow field is stable after 16 pulse cycles. Zhao et al. [12] studied the distributions of the magnetic field, flow field, and temperature field in pure aluminum under surface-pulsed magneto-oscillation. The numerical results showed that the electromagnetic force results in cyclic tensile and compressive loads and induced intensive forced convection, and that the surface oscillations induced by the electromagnetic force further results in grain refinement. Chen et al. [13] simulated the solidification characteristics of $\mathrm{Al}-15 \mathrm{wt} . \%$. Cu alloy under the PMF and found that the maximum velocity appeared near the side of the melt. The heat extraction of the melt is dominated by the forced convection at the liquid stage and early stage of solidification, thus resulting in a very uniform temperature field.

The above simulations only considered the melts themselves [7-13]. The material parameters such as resistivity used to calculate the magnetic field and electromagnetic force in the above calculation mode were those of the pure melt. The electromagnetic force is calculated first, and then it is loaded into the subsequent calculation of the flow field and temperature field. However, the electromagnetic force on the melt would change as the solid phase appears during solidification, which is possibly because of the difference in the resistivity between the solid phase and liquid phase, and the distributions of the flow field and temperature field will be thus affected.

The influences of the pulsed magnetic field on the interface have also been studied. Liao et al. [14] investigated the effects of electric current pulse on the stability of the solid-liquid interface of Al-4.5 wt.\% Cu alloy in directional solidification, and the experimental results show both the cellular spacing and the mushy zone depth decrease with increasing pulse current density. Song et al. [15] studied the effects of electric current pulse on the microstructure of directionally solidified Al-4.5 wt.\% $\mathrm{Cu}$ alloy. Their experimental results indicate that electric current pulse can make the convex solid-liquid interface flat, and reduce the primary arm spacing and the depth of mushy zone. Besides, Song et al. [16] studied the effect of a pulsed magnetic field on the microstructure of austenitic stainless steel in directional solidification, and the experimental results show that the application of the pulsed magnetic field destabilize the interface morphology [16]. However, the relevant numerical simulation calculations are few for the influence of the pulsed magnetic field on the melt in the presence of the solid-liquid interface.

Therefore, the influence of the PMF on the melt with the solid-liquid interface needs to be further investigated. The superalloy K4169 solidified in a Bridgeman furnace with and without the PMF was studied through experiments in this paper. A three-dimensional mathematic model that coupled the electromagnetic field, fluid flow and temperature field was constructed to investigate the influence of the PMF on the superalloy melt with the solid-liquid interface. The distributions of the electromagnetic force and flow field in the melt without the solid-liquid interface were also studied for comparison.

\section{Mathematic Model}

\subsection{Physical Entity and Parameters}

The solidification equipment and the finite element model used for simulation are shown in Fig. 1. The solidification equipment is composed of a PMF coil, an induction heating device, and a withdrawal system. The inner diameter, outer diameter, and height of the coil are $50 \mathrm{~mm}$, $70 \mathrm{~mm}$, and $50 \mathrm{~mm}$, respectively. The graphite sleeve can shield the magnetic field produced by the induction heating furnace [17]. Besides, the device used for generating the pulsed magnetic field was located below the graphite sleeve to ensure that the pulsed magnetic field is simply applied to the melt. So the induction heating furnace has little effect on the pulsed magnetic field. The shape of the solid-liquid interface is meniscus, which is confirmed by the water quenching experiment when the sample was pulled for $45 \mathrm{~mm}$ in directional solidification, as shown in Fig. 1b. A three-dimensional finite element model (Fig. 1c) was built based on the solidification equipment, and the solid-liquid interface is in the center of the coil. The variation in the pulsed current density in the coil is shown in Fig. 2. The current is divided into three stages: an ascending stage, a descending stage, and a pause stage. The density of peak current is $3 \times 10^{7} \mathrm{~A} / \mathrm{m}^{2}$, and the pulse frequency is $5 \mathrm{~Hz}$. The resistivity is used to distinguish the solid and liquid phases in this paper. The parameters used to calculate the distribution of the electromagnetic field and the temperature field are shown in Tables 1 and 2 , respectively. The emissivity is 0.9 , and the melt viscosity is $0.004 \mathrm{~Pa} \cdot \mathrm{s}$. 


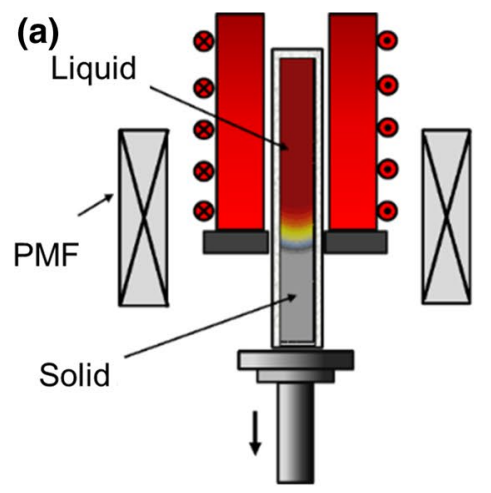

(b)

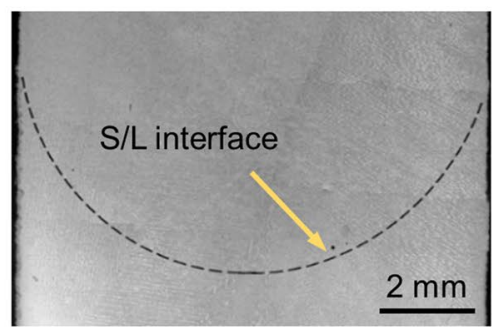

(c)

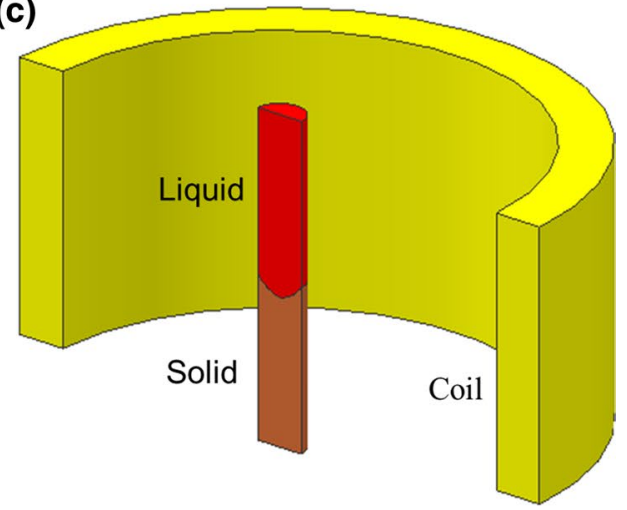

Fig. 1 Sketch of directional solidification equipment a, the liquid melt quenching sample with meniscus solid-liquid interface b, the finite element model c

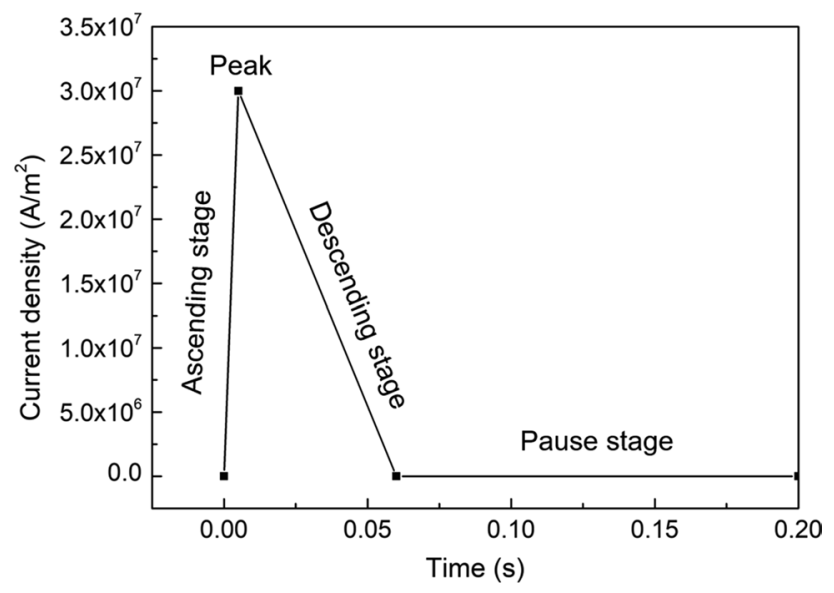

Fig. 2 Variation in pulsed current density through the coil

Table 1 Material parameters for the electromagnetic simulation

\begin{tabular}{lll}
\hline- & Resistivity $(\Omega \cdot \mathrm{m})$ & Permeability \\
\hline Liquid & $1.19 \times 10^{-6}$ & 1 \\
Solid & $6 \times 10^{-7}$ & 1 \\
Coil & $2 \times 10^{-8}$ & 1 \\
Air & - & 1 \\
\hline
\end{tabular}

Table 2 Material parameters for the temperature simulation

\begin{tabular}{lllll}
\hline Material & $\begin{array}{l}\text { Temperature } \\
(\mathrm{K})\end{array}$ & $\begin{array}{l}\text { Density } \\
\left(\mathrm{kg} / \mathrm{m}^{3}\right)\end{array}$ & $\begin{array}{l}\text { Thermal } \\
\text { conductivity } \\
(\mathrm{J} /(\mathrm{kg} \mathrm{K}))\end{array}$ & $\begin{array}{l}\text { Enthalpy }(\mathrm{kJ} / \\
\mathrm{kg})\end{array}$ \\
\hline Superalloy & 300 & 8150 & 10 & 592 \\
& 1523 & 7800 & 30 & 844 \\
& 1613 & 7800 & 30 & 1130 \\
& 1800 & 7800 & 30 & 1243 \\
Mold & $300-1800$ & 4000 & 6 & 1250 \\
\hline
\end{tabular}

\subsection{Governing Equations}

The following equations can express the governing Maxwell equations of the electromagnetic field:

$\nabla \times \boldsymbol{H}=\boldsymbol{J}+\frac{\partial \boldsymbol{D}}{\partial t}$,

$\nabla \times \boldsymbol{E}=-\frac{\partial \boldsymbol{B}}{\partial t}$,

$\nabla \cdot \boldsymbol{B}=0$

$\nabla \cdot \boldsymbol{D}=\rho$.

The Lorentz force can be calculated by the following equation:

$f=\mu_{0} \boldsymbol{J} \times \boldsymbol{H}$,

$\boldsymbol{J}=\sigma \boldsymbol{E}$.

The continuity equation, the momentum equation, and the incompressible energy equation are described in Eqs. (7)-(9), respectively.

$\frac{\partial \rho}{\partial t}+\nabla \cdot(\rho \vec{V})=0$

$\frac{\partial(\rho v)}{\partial t}=-\nabla \cdot(\rho v \boldsymbol{v})-\nabla p-\mu \nabla^{2} \boldsymbol{v}+\rho F$,

$\frac{\partial\left(\rho C_{p} T\right)}{\partial t}+\nabla \cdot\left(\rho C_{p} v T\right)=\nabla \cdot(K \nabla T)+Q_{V}$.

The boundary conditions of the melt are given by:

On the top surface: $V_{\mathrm{z}}=0$; 
At the bottom and side surface: $V_{x}=0, V_{y}=0, V_{z}=0$;

\subsection{Model Validation}

Moore et al. [18] have reported the experimental measurements for the fluid flow with the magnetic field, and the experimental results provided important reference data. In the experiment, alternating current with a root mean square of $1900 \mathrm{~A}$ and a frequency of $50 \mathrm{~Hz}$ was fed to the induction coil. The apparatus consisted of a water-cooled stainlessvessel containing mercury approximately $0.3 \mathrm{~m}$ in diameter and $0.3 \mathrm{~m}$ high. With the same conditions, the corresponding model was carried out in this paper. The resistivity, permeability, and viscosity of mercury are $9.6 \times 10^{-7} \Omega \cdot \mathrm{m}, 1$, and $0.0015 \mathrm{~Pa} \cdot \mathrm{s}$, respectively. Three sets of meshes for the melt were used to test the grid independence. The predicted and measured axial velocity components along the radius at the height of $0.225 \mathrm{~m}$ are quantitatively given in Fig. 3. The figure shows that the simulated results do not change much with the grid size, and the $1 \mathrm{~mm} \times 1 \mathrm{~mm} \times 1 \mathrm{~mm}$ mesh is sufficient to obtain a good agreement with experimental results.

\section{Experimental}

The alloy ingot of a nickel-based superalloy K4169 was prepared with a vacuum induction furnace with chemical compositions (wt.\%) being: $\mathrm{Co} 12, \mathrm{Cr} 18$, Ti 1.0, $\mathrm{Al} 0.5$, Mo 3, Ta 3, C 0.015, B 0.018, Nb 4, and Ni balanced. The cast samples were cut and enveloped in corundum tubes with an inner diameter of $10 \mathrm{~mm}$, a height of $100 \mathrm{~mm}$, and a thickness of $2 \mathrm{~mm}$. In the directional solidification, the superalloy K4169 was melted completely firstly, and then, after it was held for $10 \mathrm{~min}$ at $1648 \mathrm{~K}$, the molten metal was withdrawn

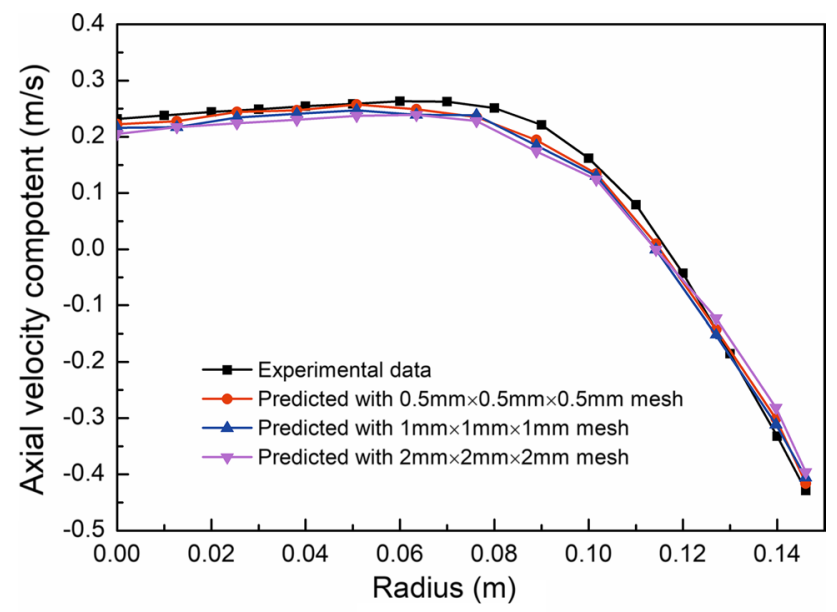

Fig. 3 A comparison of the experimentally measured and theoretically predicated radial variation in the axial velocity component at the height of $0.225 \mathrm{~m}$ from the Bridgman furnace at the speed of $0.75 \mathrm{~mm} / \mathrm{s}$ without and with the PMF, respectively. The Bridgeman furnace was fluxed with high purity argon to prevent the melt from oxidation during the experiments. The directionally solidified specimens were polished and then etched by a solution of $15 \mathrm{~g} \mathrm{CuSO}_{4}+3.5 \mathrm{ml} \mathrm{H}_{2} \mathrm{SO}_{4}+50 \mathrm{ml} \mathrm{HCl}$ for microstructure observation with a scanner (ScanMaker i800plus) and an optical microscope (ZEISS Axio Observer. Z1m).

\section{Results and Discussion}

\subsection{Simulation the Effect of the PMF on Superalloy Melt in Directional Solidification}

\subsubsection{Electromagnetic Force}

Figure 4 indicates the distribution of the electromagnetic force in the melt with the solid-liquid interface under the PMF. The compressive force of the sample increases in the ascending stage (Fig. 4a), and the pulling force decreases in the descending stage (Fig. 4c). In addition, the electromagnetic force in the pause stage is several orders of magnitude lower than that in the ascending stage (Fig. 4d). The evolution of the electromagnetic force along the radial direction at point A during a single period is shown in Fig. 5. The maximum compressive force is approximately ten times the maximum pulling force because the current density changes faster in the ascending stage, thus increasing the velocity of melt flow and inducing a strong shear force in the melt. Besides, the electromagnetic force is greater at the edge of the sample than that at the center due to skin effect.

The evolution of the electromagnetic force along the radial direction is similar to that in previous studies $[8,11$, 13]. However, its distribution near the solid-liquid interface is different from that in previous researches. Figure 6 shows the change of electromagnetic force with and without a solid-liquid interface along the red dotted line, which is $1 \mathrm{~mm}$ from the edge at peak. The largest electromagnetic force in the melt appears near the solid-liquid interface. There is an electromagnetic force gradient in front of the solid-liquid interface because of the existence of the solid-liquid interface. The electromagnetic force gradually decreases from point $\mathrm{B}$ to point $\mathrm{C}$ as the density of magnetic flux decreases.

The induced current is generated when the alloy is placed in a changing magnetic field. According to Faraday's law of electromagnetic induction, an induced magnetic field is also generated by the induced current, and its direction is opposite to that of the original magnetic field. When an alloy containing both solid and liquid phases is placed in a pulsed magnetic field, the induced currents $I_{1}$ and $I_{2}$ will be generated in the liquid and solid phase, 

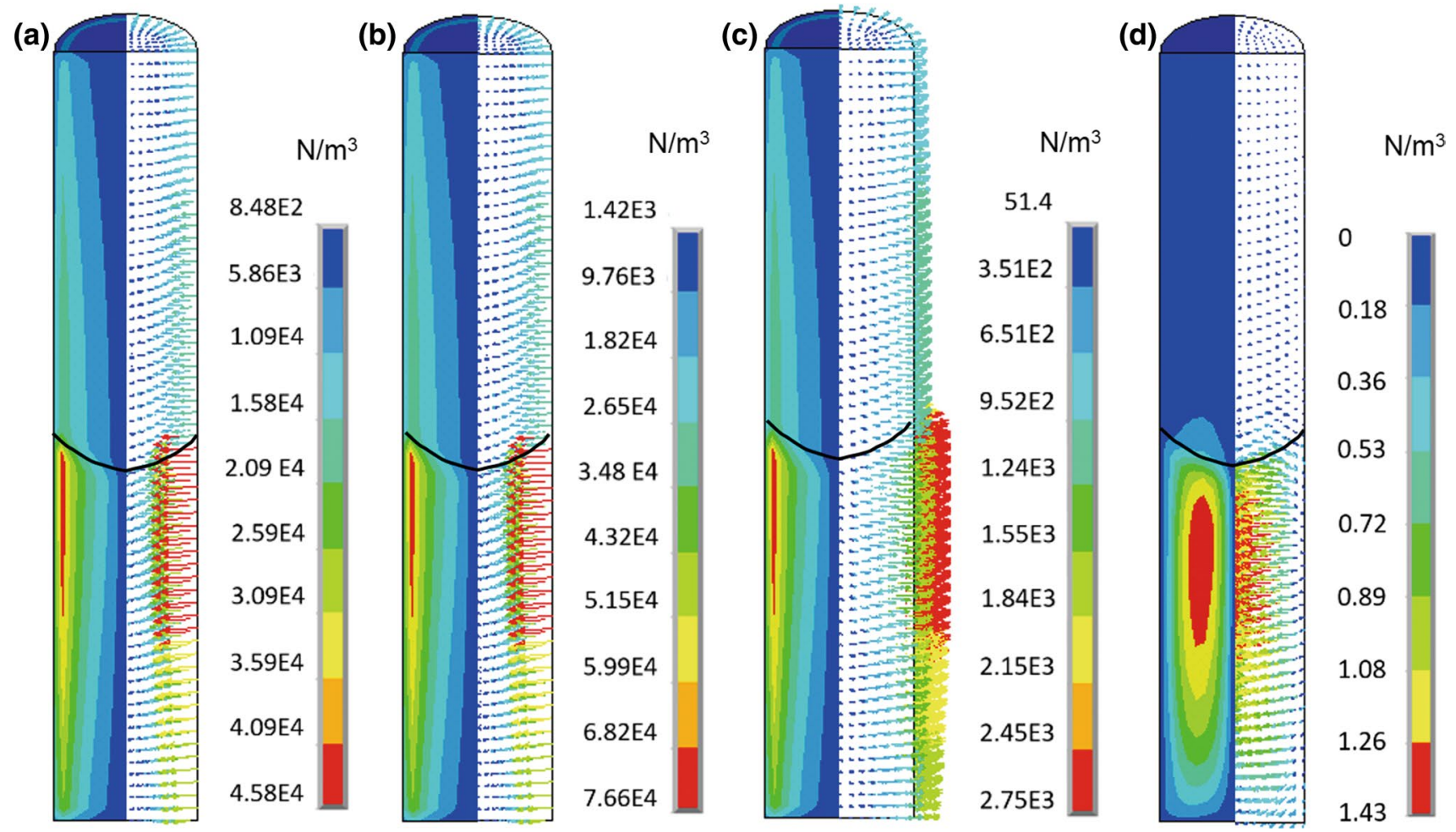

Fig. 4 Distribution of the electromagnetic force at mid of ascending stage $\mathbf{a}$, at peak $\mathbf{b}$, at mid of descending stage $\mathbf{c}$, at mid of pause stage $\mathbf{d}$

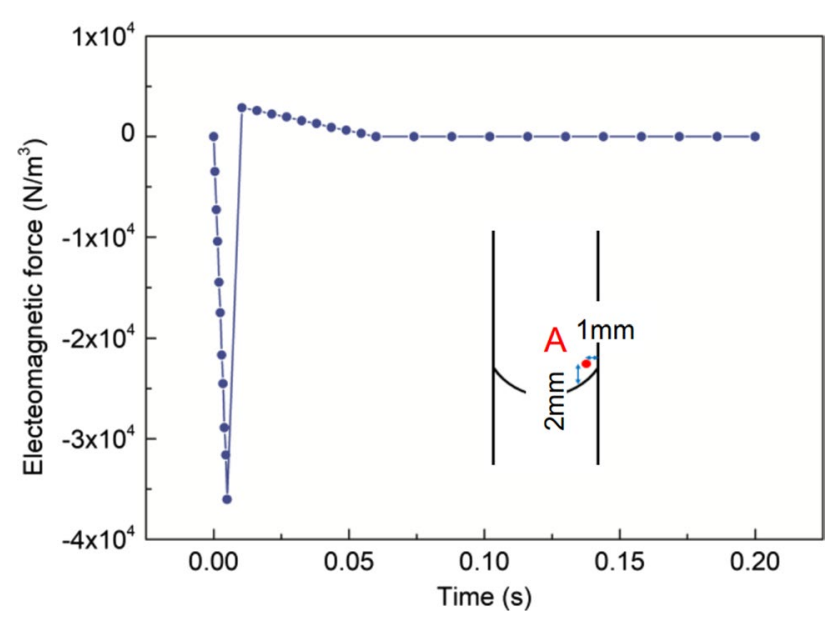

Fig. 5 Evolution of the electromagnetic force at point A in one period

respectively, as shown in Fig. 7. The induced current $I_{2}$ is greater than $I_{1}$ because the conductivity of the solid phase is greater than that of the liquid phase. The induced magnetic field generated by $I_{2}$ in the solid phase will reduce the total magnetic flux and the rate change of the magnetic flux in the liquid phase in front of the solid-liquid interface [19].

The induced electromotive force can be calculated by the following equation: $\varepsilon=n \frac{\Delta \varphi}{\Delta t}$.

The rate of the magnetic flux change in the liquid near the solid-liquid interface may be reduced because the conductivity of the solid phase and liquid phase is different. Therefore, the induced electromotive force in the liquid close to the solid-liquid interface will decrease, thus possibly resulting in a decrease in induced current in that area. According to Eq. (5), the electromagnetic force in the liquid near the solid-liquid interface will be reduced because induced current and magnetic flux decrease. As a result, the largest electromagnetic force in the liquid phase appears in front of the solid-liquid interface.

\subsubsection{Electromagnetic Vibration}

The variation in the magnetic pressure in one pulse period is shown in Fig. 8. There is periodic positive and negative pressure in the melt. A negative pressure is exerted from the center to the surface of the melt during the ascending stage (Fig. 8a) while a positive pressure from the surface to the center during descending state (Fig. 8b). The alternating pressure leads to the vibration of the melt. The mercury surface fluctuation of the melt was also observed under the PMF [9]. Besides, according to the simulation results, a larger pressure exists in front of the solid-liquid interface. 


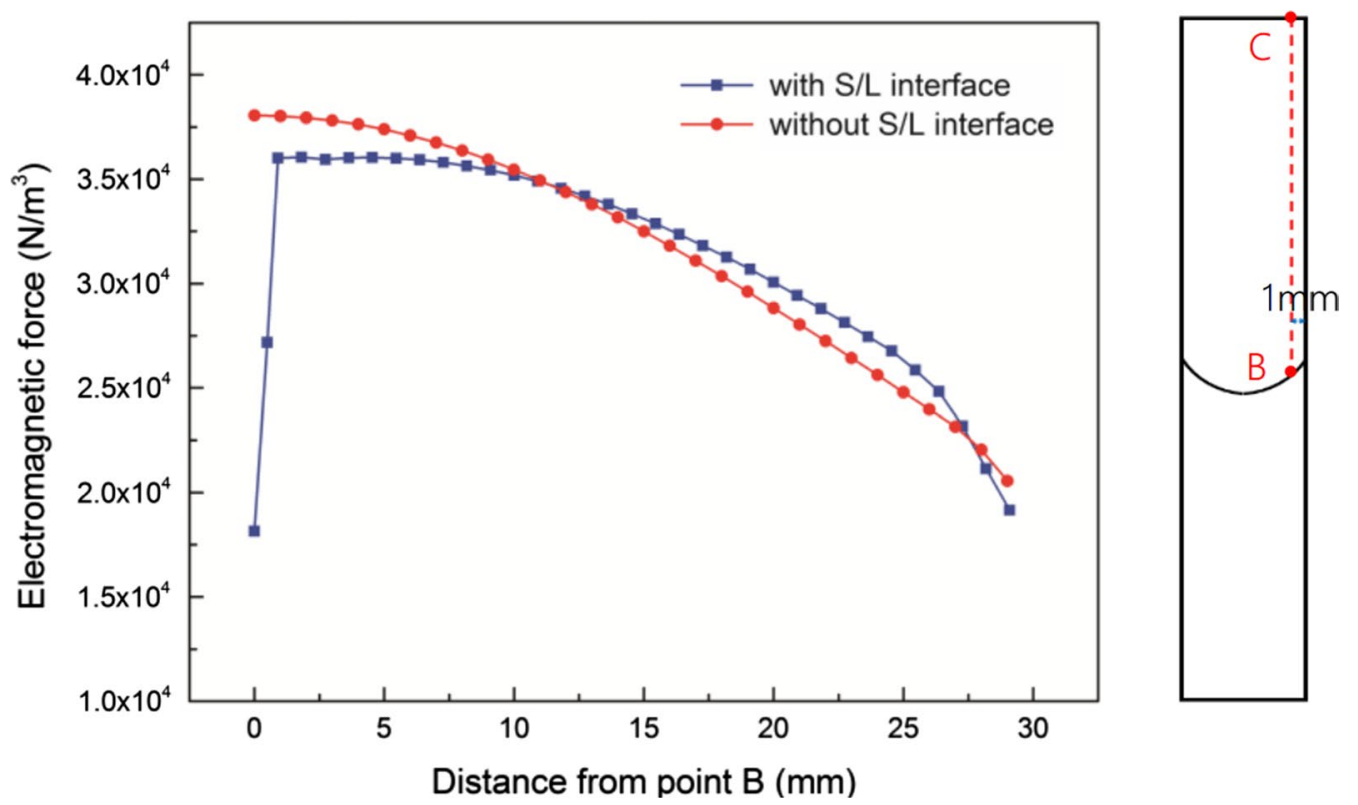

Fig. 6 Variation in the electromagnetic force without and with solid-liquid interface from point $\mathrm{B}$ to point $\mathrm{C}$ at peak

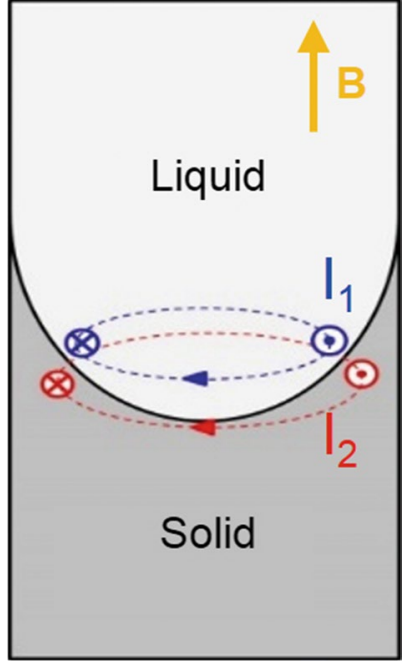

Fig. 7 Schematic illustration of the induced current

The distribution of the magnetic pressure in the melt without the solid-liquid interface during one pulse period is shown in Fig. 9. It can be seen that there is periodic positive and negative pressure in the melt as well, but with a smaller pressure. The changes of the pressure with time at points $\mathrm{D}$ and $\mathrm{E}$ in the melt with and without the solid-liquid interface are shown in Fig. 10. The change of pressure is more intensive if the solid-liquid interface is taken into account. In particular, the change of the pressure at the edge of the sample with the solid-liquid interface increases by about $50 \%$. Therefore, the effect of the electromagnetic vibration can be more accurately reflected when the solid-liquid interface is considered.

\subsubsection{Melt Convection and Temperature Field}

The distribution of the melt flow with the solid-liquid interface during one pulse period is shown in Fig. 11a-c. The flow velocity is the largest at the peak because the electromagnetic force increases continuously in the ascending stage. The direction of the electromagnetic force is the opposite in the descending stage, so the flow velocity is reduced. It keeps slowing down in the pause stage owing to the melt viscosity. There is an obvious periodic convection flow in front of the solid-liquid interface. The flow velocity near the solid-liquid interface is larger. Figure $11 \mathrm{~d}$ shows the distribution of flow field without the solid-liquid interface at the end of the ascending stage. The melt is driven to move inward due to the compressive electromagnetic force at the edge of the melt during the ascending stage, and then, it flows up and down at the center, forming a multi-circle convection on the longitudinal section, with the largest flow velocity at the center.

The evolution of the flow velocity with time at point $\mathrm{F}$ (Fig. 11a) and point G (Fig. 11c) is shown in Fig. 12a. The flow velocity of the melt reaches a quasi-steady state after 15 pulse cycles. The fluctuation of the flow velocity is notable at both points. The flow velocity is much greater at point $\mathrm{F}$ than at point $\mathrm{G}$. The variation in the acceleration with time at the two points is presented in Fig. 12b, which reveals the net force imposed on the melt. The direction of the net force changes periodically, which further proves that the melt is subjected to periodic pressure and pulling force. The maximum net force at point $\mathrm{F}$ is about ten times greater than that at point $\mathrm{G}$. 


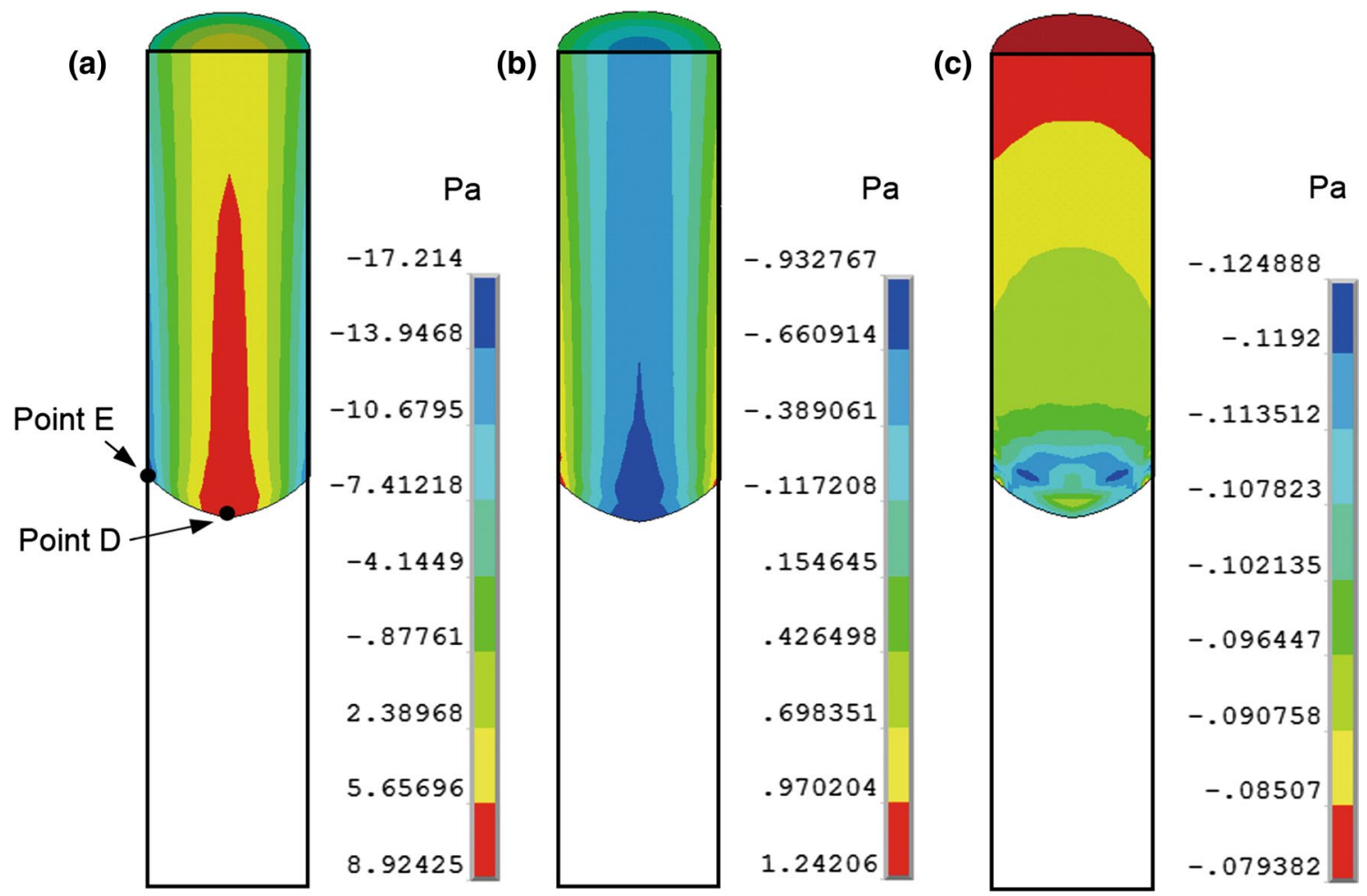

Fig. 8 Distribution of the magnetic pressure in the melt with the solid-liquid interface during the ascending stage a, during the descending stage b, during the pause stage $\mathbf{c}$

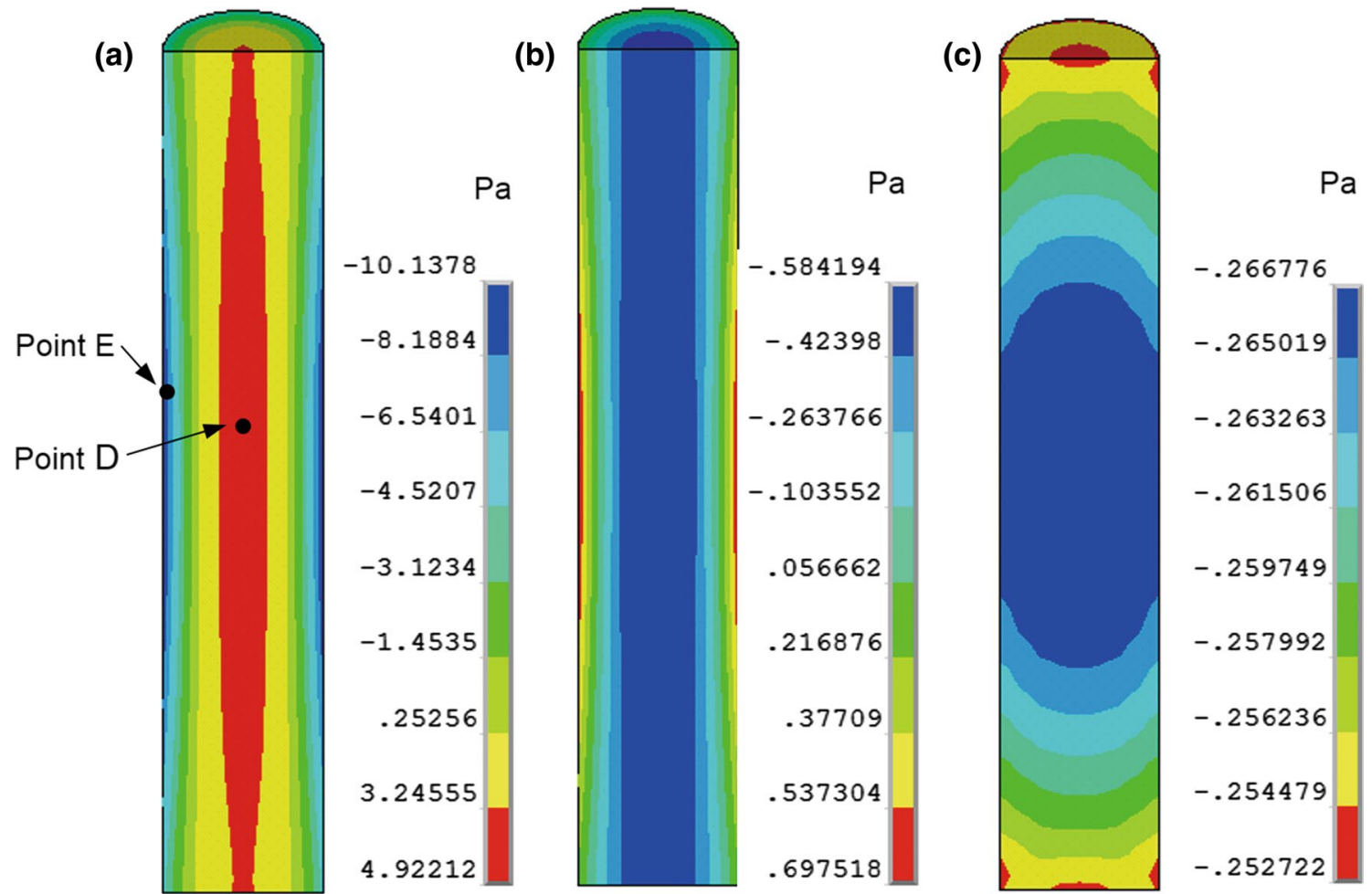

Fig. 9 Distribution of the magnetic pressure in the melt without the solid-liquid interface during the ascending stage a, during the descending stage $\mathbf{b}$, during the pause stage $\mathbf{c}$ 


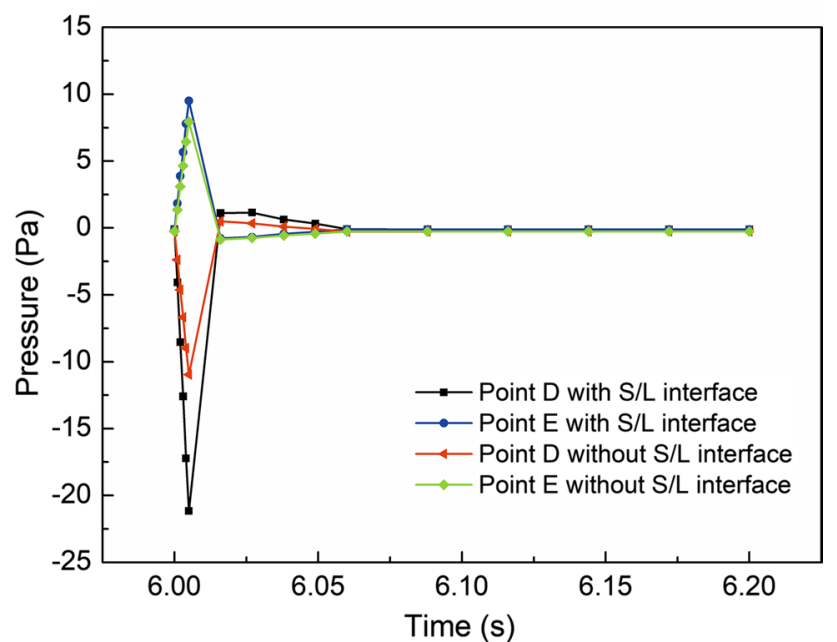

Fig. 10 Variation in the magnetic pressure with time at points D, E

Figure 13 shows the distribution of the flow velocity of the melt along the axial direction, which is $1.5 \mathrm{~mm}$ from the edge (Fig. 13a) at the peak when the solid-liquid interface is considered. The flow velocity near the solid-liquid interface is the largest because there is the largest electromagnetic force. When the melt is far away from the solid-liquid interface, the flow velocity decreases rapidly. The solidification front will be flushed more strongly by the melt convection, resulting in the detachment and dispersion of grain fragments from the solidification front.

The flow pattern of fluid can be classified into the laminar flow and turbulent flow, based on the magnitude of the Reynolds number $(\mathrm{Re})$. The mathematical formula of $\mathrm{Re}$ is given by:

$\operatorname{Re}=\frac{v \rho d}{\mu}$,

where $d$ is the diameter of the pipe, $v$ the flow velocity, $\rho$ the density, and $\mu$ the dynamic viscosity.

According to fluid mechanics, when Re $>2300$, the flow pattern of fluid is turbulent flow, and when $\operatorname{Re} \ll 2300$, the flow pattern of fluid is laminar flow. Re is about 57 in this paper; thus, the melt flow caused by the PMF is laminar.

The distribution of the temperature field is affected by the forced convection of the melt, which helps hegemonize the melt temperature and reduce the temperature gradient in front of the solid-liquid interface. Figure 14 shows the distributions of the temperature field in the melt without and with the PMF. According to the simulation results, the curvature of the solid-liquid interface decreases, and the solid-liquid interface tends to be flat with the PMF (the black dotted line in the figure is solidus). To confirm the influence of the PMF on the temperature distribution, the shapes of the solid-liquid interface without and with
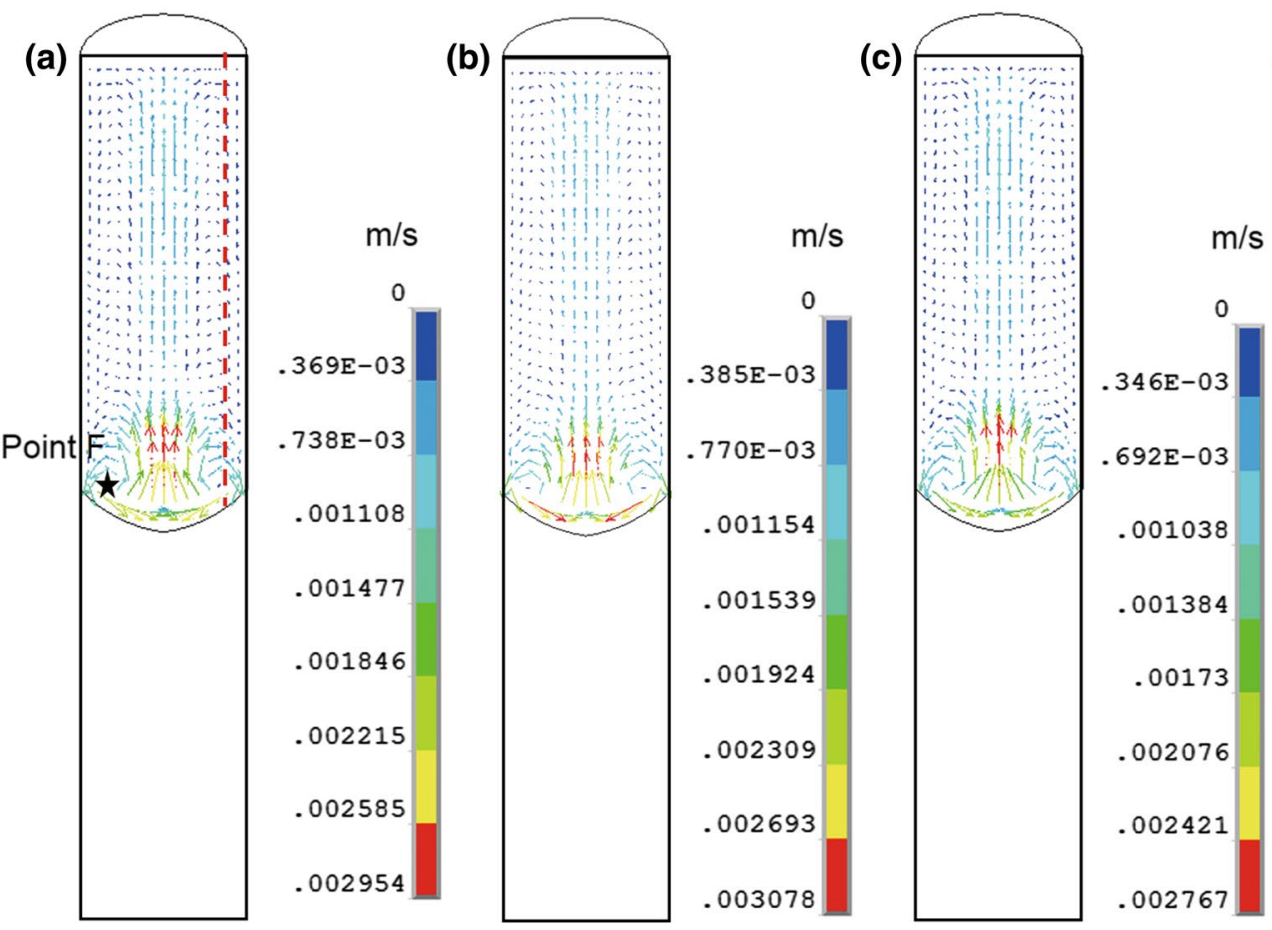

(d)

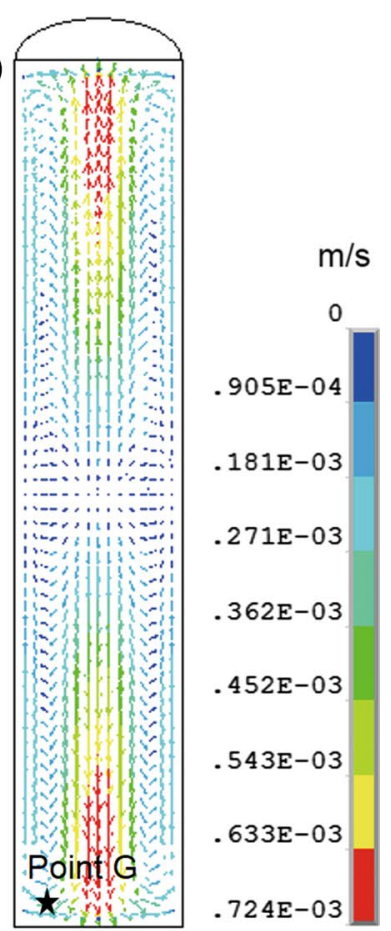

Fig. 11 Flow field with the solid-liquid interface at the end of the ascending stage $\mathbf{a}$, at the end of the descending stage $\mathbf{b}$, and the end of the pause stage $\mathbf{c}$. The flow field without the solid-liquid interface at the end of the ascending stage $\mathbf{d}$ 

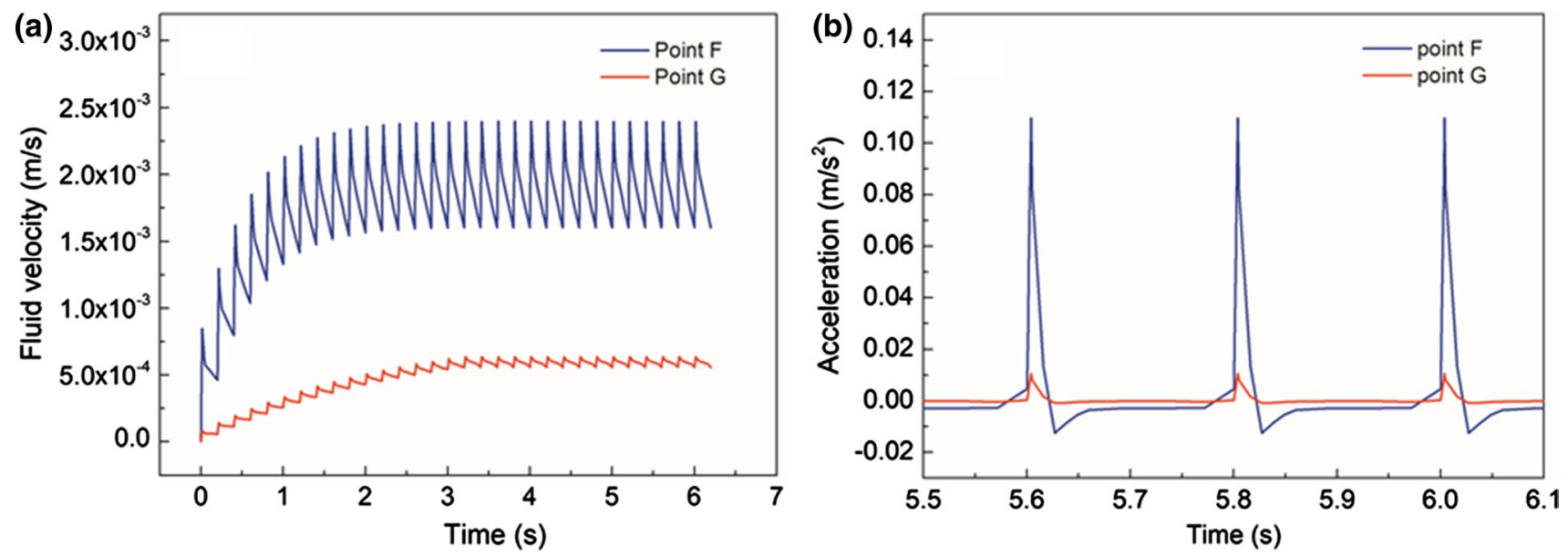

Fig. 12 Evolution of the flow velocity a, acceleration $\mathbf{b}$ with time at points $\mathrm{F}$ and $\mathrm{G}$

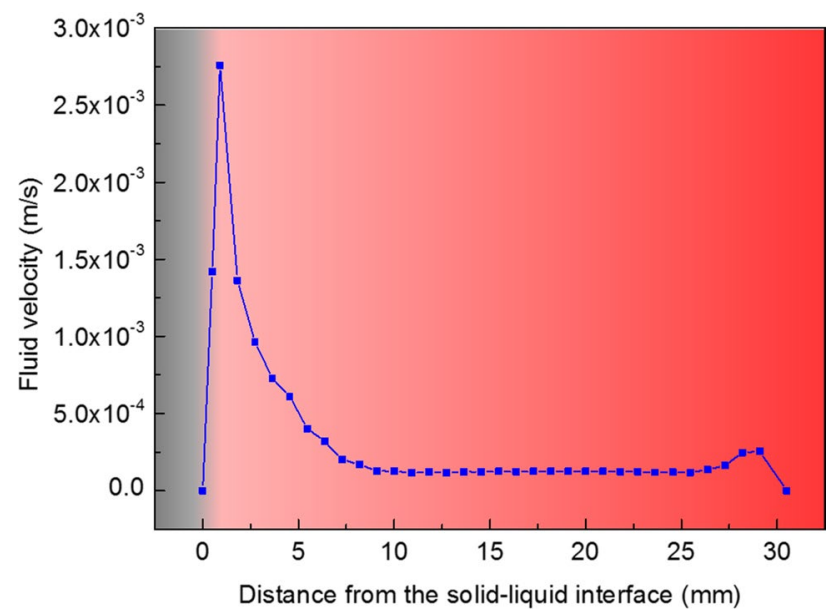

Fig. 13 Distribution of the flow velocity along the axial direction

the PMF were obtained by liquid metal quenching experiments, as shown in Fig. 15 (the black dotted line in the figure is for the solid-liquid interface). It is confirmed that the curvature of the solid-liquid interface decreases with application of the PMF, which is consistent with the simulation results.

As the volume of the liquid phase decreases during directional solidification, it is necessary to study the distribution of the flow field in the melt with different liquid phase volumes. As shown in Fig. 16 the simulation results indicate that the flow field is stable, but the flow velocity increases slightly as the volume of liquid phase decreases.

\subsubsection{Joule Heat}

Figure 17 shows the distribution of the Joule heat in the sample. The Joule heat in the ascending stage is greater (a)

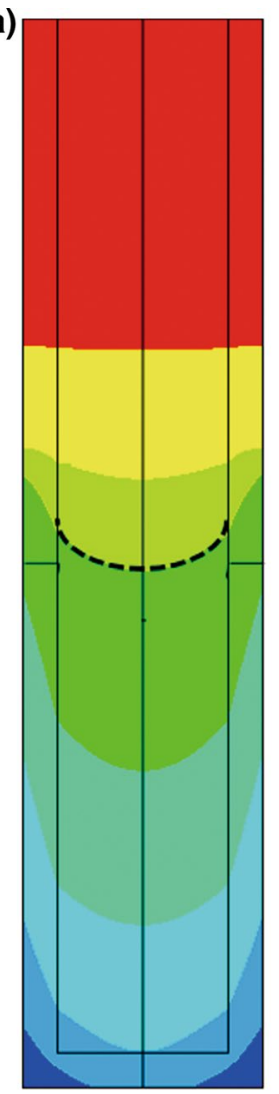

(b)

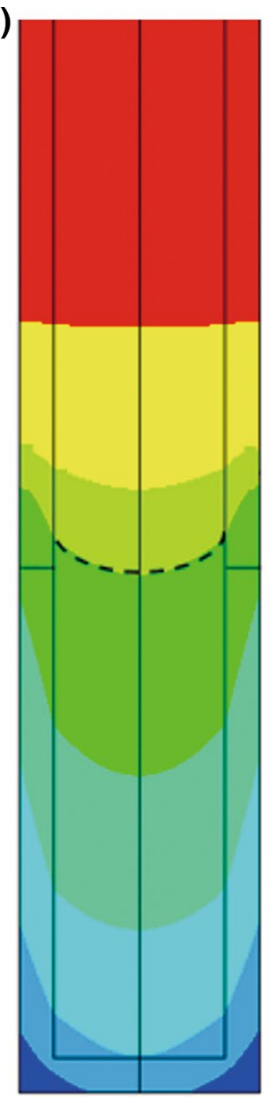

Fig. 14 Distribution of the temperature field without the PMF a, with the PMF b

than that in the descending stage because the PMF changes more rapidly in the ascending stage. It is mainly concentrated near the surface of the sample due to skin effect. Besides, the Joule heat in the solid phase is significantly 
(a)

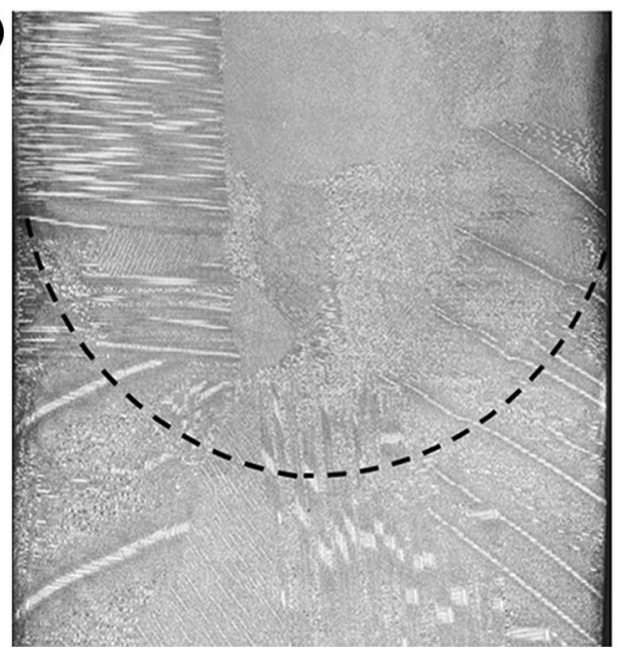

Fig. 15 Shape of the solid-liquid interface without PMF a, with PMF b

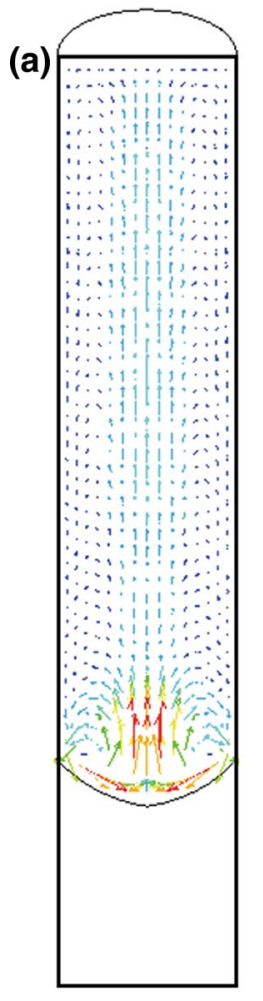

(a)

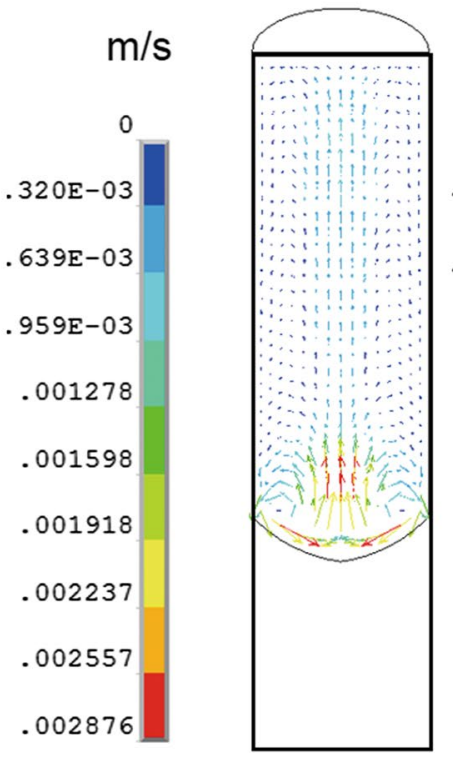

(b)

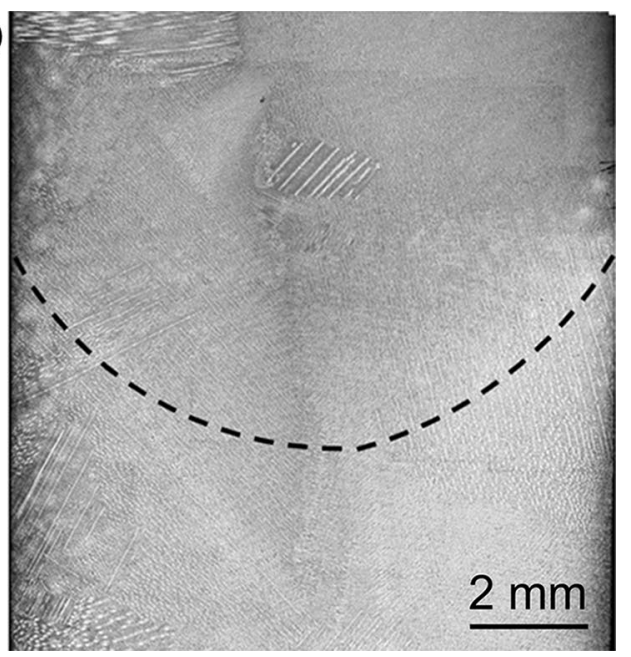

(c)

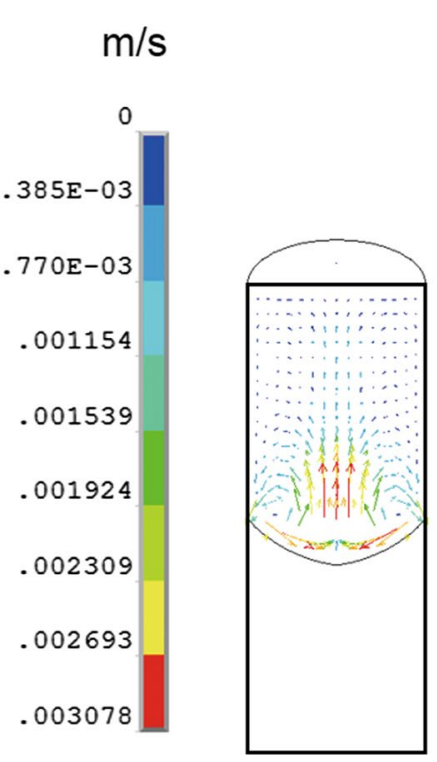

$\mathrm{m} / \mathrm{s}$<smiles>[C+]CCC</smiles>

$.352 \mathrm{E}-03$

$.704 \mathrm{E}-03$

.001055

.001407

.001759

.002111

.002462

.002814

.003166

Fig. 16 Evolution of the flow field with different liquid phase volumes

higher than that in the liquid phase. The induced current in the solid phase is approximately twice that of in the liquid phase, although the resistance of the solid phase is half that of the liquid phase. The Joule heat under PMF may be helpful to reduce the temperature gradient in front of the solid-liquid interface.

\subsection{Microstructural Refinement and Refining Mechanism}

\subsubsection{Microstructural Refinement of Superalloy K4169}

The longitudinal section microstructures of the directionally solidified superalloy K4169 with and without the PMF 
(a)

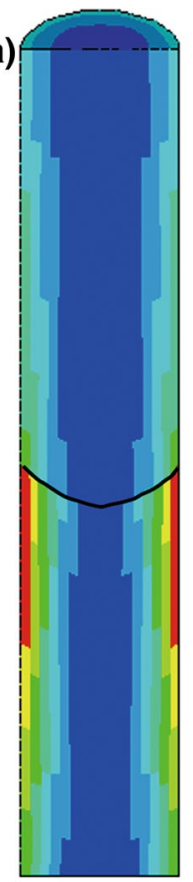

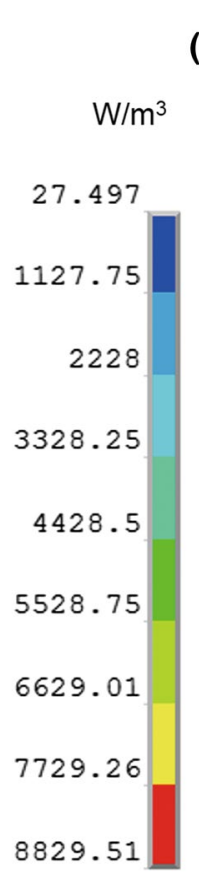

(b)

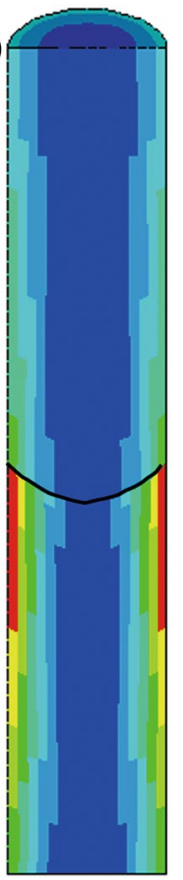

$\mathrm{W} / \mathrm{m}^{3}$

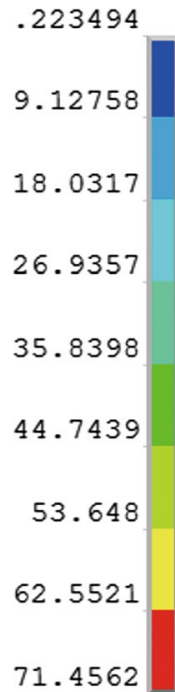

Fig. 17 Distributions of the Joule heat at mid of ascending stage a, at mid of descending stage $\mathbf{b}$

are shown in Fig. 18. Without the PMF, the solidification structure of the specimen consists of nearly wholly coarse columnar grains, while it changes to fine equiaxed grains with application of the PMF. It is certain that a transition from columnar to equiaxed grain structure is caused by the PMF.

\subsubsection{Refining Mechanism of the PMF}

The present work focuses on how the PMF causes grain refinement in directional solidification of superalloy K4169 when considering the solid-liquid interface. The PMF may increase the nucleation rate and increase the probability of nucleus survival. It is generally believed that the electromagnetic force, electromagnetic vibration, and forced convection are favorable for grain refinement, such as a direct action of the electromagnetic force on the mushy zone is supposed to break the dendrites into small fragments owing to high shear stress [20-22]. However, it is not clear which mechanism dominates.

Considering the direct action of the electromagnetic force, the numerical analysis presented in Sect. 4.1.1 indicates that the maximum electromagnetic force in front of the solid-liquid interface is $\sim 3.6 \times 10^{4} \mathrm{~N} / \mathrm{m}^{3}$. According to Ref. [23], the minimum electromagnetic force to break the columnar dendrite of superalloy $\mathrm{K} 4169$ is about $1 \times 10^{5} \mathrm{~N} / \mathrm{m}^{3}$. Hence, the direct

(a)

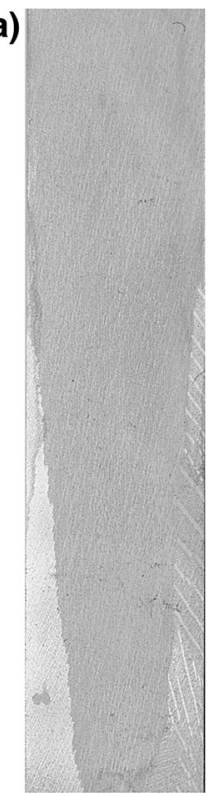

(b)

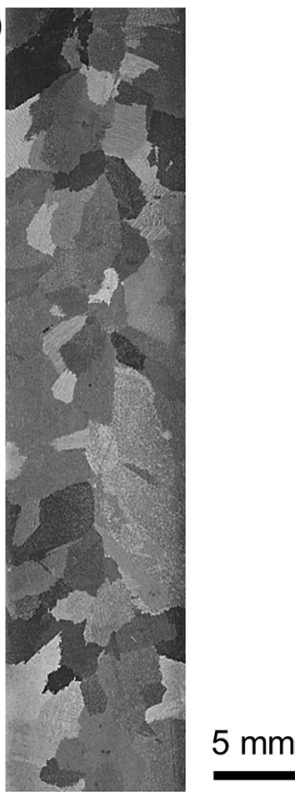

Fig. 18 Microstructures of superalloy K4169 without the PMF a, with the PMF b

action of the electromagnetic force cannot break the columnar dendrite, and it does not play a prominent role in this work.

As regard to the electromagnetic vibration, an increase in dendrite fragmentation rate was achieved by the applying a pulsed magnetic field to an array of Al-15wt.\% Cu dendrites due to electromagnetic vibration [24]. Zhao et al. [25] also found that the pulsed magneto-oscillation induced equiaxed grain sized from millimeter scale to hundreds micrometer scale, and increased the volume fraction of equiaxed grains. In this study, when considering the solid-liquid interface, the electromagnetic vibration is more severe ahead of the solidification front. The electromagnetic vibration destroys the stable growth of dendrites and promotes the detachment of the grain fragments from the solidification front [26].

The forced convection also results in grain refinement. If there is no convection in the melt, the nucleus will grow into dendrites. While, the crystal nucleus on the mold wall could be swept away by strong convection and dispersed into the entire melt due to the convection, which increases nuclei number and leads to grain refinement [27, 28]. Campanella et al. [29] formulated a criterion for dendrite fragmentation caused by the fluid flow based on partial re-melting of dendrite arms. They concluded that dendrite fragmentation occurs when the component of flow velocity $u_{1, z}$ along the thermal gradient becomes larger than the speed of the isotherms $V_{\mathrm{T}}$.

$C_{\mathrm{R}}=\frac{u_{\mathrm{l}, \mathrm{z}}}{V_{\mathrm{T}}}>1$. 
This criterion can be used as a rough estimation to answer the question of whether the forced convection in the present experiments would be sufficient to provoke dendrite fragmentation. In the present work, the speed of the isotherms is equal to the withdrawal speed of $\sim 0.75 \mathrm{~mm} / \mathrm{s}$. Without considering the solid-liquid interface, the flow velocity is less than $0.75 \mathrm{~mm} / \mathrm{s}$. On the contrary, the flow velocity in front of the solid-liquid interface along the thermal gradient is greater than $2 \mathrm{~mm} / \mathrm{s}$, which is indeed considerably higher than the isotherms speed.

Moreover, the flow velocity is larger in front of the solid-liquid interface in this work, which is more conducive to the occurrence of dendrite fragmentation. So the forced convection in front of the solid-liquid interface provokes dendrite fragmentation and promotes the broken dendrite arm to disperse in the melt acting as new nuclei. Therefore, when studying the influence of the PMF on the flow field, the influence of the solid-liquid interface needs to be considered.

Furthermore, the forced convection is concentrated in front of the solid-liquid interface, which leads to a more uniform temperature distribution and a lower temperature gradient in front of the solid-liquid interface. The reduction in temperature gradient can promote the formation of equiaxed grains [30]. Additionally, the PMF induces the fluid to flow toward the front of the solid-liquid interface, which will decrease the liquid composition ahead of the columnar front. Accordingly, the local equilibrium temperature augments, and the constitutional undercooling in front of the solid-liquid increases. High undercooling and low thermal gradients will favor grain refinement because the probability of dendrite fragments surviving is larger with the increasing extent of the undercooled region [31].

The distribution of Joule heat on both sides of the solid-liquid interface under the PMF will reduce the temperature gradient in front of the solid-liquid interface. However, the simulated results in this paper indicate that the effect of Joule heat on the temperature field is very small. The local input from Joule heat in the liquid reaches maximum values of $\sim 4500 \mathrm{~W} /$ $\mathrm{m}^{3}$, as seen from Fig. 17. Estimations concerning the heat production by the phase change from liquid to solid deliver much larger values of $\sim 4500 \mathrm{~W} / \mathrm{m}^{3}$. The difference of Joule heat in the solid phase and liquid phase is $\sim 4300 \mathrm{~W} / \mathrm{m}^{3}$. Under adiabatic conditions and for a period of $60 \mathrm{~s}$, the temperature difference between the solid phase and the liquid phase only caused by Joule heat is less than $0.02 \mathrm{~K}$, so the decrease in the temperature gradient in front of solid-liquid interface caused by Joule heat is negligible.

\section{Conclusions}

1. The PMF generates periodic electromagnetic compressive and pull forces in the melt, and the position with the largest electromagnetic force is in front of the solidliquid interface. The electromagnetic vibration is more intensive ahead of the solidification front in directional solidification when considering the solid-liquid interface.

2. There are forced convections in front of the solid-liquid interface, and the flow velocity is larger ahead of the solidification front in directional solidification with the solid-liquid interface. The forced convection homogenizes the temperature field in the melt.

3. Remarkable structure refinement of superalloy K4169 in directional solidification is achieved when the PMF is applied, and the morphology is changed to wholly equiaxed grains. The electromagnetic vibration and melt convection in front of the solid-liquid interface induced by the electromagnetic force are the main reasons for grain refinement.

Acknowledgements This work is financially supported by the National Natural Science Foundation of China (No. 51674236), the Key Research and Development Program of Liaoning Province (No. 2019JH2/10100009), the National Science and Technology Major Project (No. 2017-VI-0003-0073), and the National Key Research and Development Program (No. 2018Y-FA0702900).

\section{References}

[1] Y.J. Li, X.P. Ma, Y.S. Yang, Trans. Nonferrous Met. Soc. China 21, 1277 (2011)

[2] Q.S. Li, C.J. Song, H.B. Li, Q.J. Zhai, Mater. Sci. Eng. A 466, 101 (2007)

[3] R. Haghayeghi, P. Kapranos, Mater. Lett. 151, 38 (2015)

[4] L. Zhang, W. Li, J.P. Yao, H. Qiu, Mater. Lett. 66, 190 (2012)

[5] B. Wang, Y.S. Yang, J.X. Zhou, W.H. Tong, Rare Metal Mat. Eng. 38, 519 (2009)

[6] W. Fu, Y.S. Yang, Mater. Lett. 67, 252 (2012)

[7] A.F. Kolesnichenko, A.D. Podoltsev, I.N. Kucheryavaya, ISIJ Int. 34, 715 (1994)

[8] B. Wang, Y.S. Yang, W.H. Tong, Trans. Nonferrous Met. Soc. China 20, 283 (2010)

[9] X.P. Ma, Y.S. Yang, B. Wang, Int. J. Heat Mass Tran. 52, 5285 (2009)

[10] X.P. Ma, Y.J. Li, Y.S. Yang, J. Mater. Res. 24, 3174 (2009)

[11] Y.F. Teng, X.H. Feng, Y.J. Li, Y.S. Yang, Mater. Res. Innov. 18, 352 (2014)

[12] J. Zhao, Y.F. Cheng, K. Han, X.Z. Zhang, Z.S. Xu, Q.J. Zhai, J. Mater. Process. Technol. 229, 286 (2016)

[13] Q. Chen, H.F. Shen, Int. J. Heat Mass Tran. 120, 997 (2018)

[14] X.L. Liao, Q.J. Zhai, C.J. Song, W.J. Chen, Y.Y. Gong, Mater. Sci. Eng. A 466, 56 (2007)

[15] C.J. Song, Y.Y. Guo, Y.H. Zhang, H.X. Zheng, M. Yan, Q.Y. Han, Q.J. Zhai, J. Cryst. Growth 324, 235 (2011) 
[16] C.J. Song, Q.S. Li, H.B. Li, Q.J. Zhai, Mater. Sci. Eng. A 403, 485 (2008)

[17] P.P. Wang, H.M. Lu, Y.S. Lai, J. Cryst. Growth 96, 390 (2014)

[18] D.J. Moore, J.C.R. Hunt, Proceedings of IUTAM Symposium on Metallurgical Application of MHD (Cambridge, London, 1982), p. 93

[19] F.F. Tang, H.S. Lopez, F. Freschi, S. Elliot, Y. Li, M. Fuentes, F. Liu, M. Repetto, S. Crozier, J. Magn. Reson. 242, 86 (2014)

[20] G. Chen, J.T. Li, G.M. Xu, Acta Metall. Sin. -Engl. Lett. 31, 55 (2018)

[21] Y. Hou, Z.Q. Zhang, W.D. Xuan, J. Wang, J.B. Yu, Z.M. Ren, Acta Metall. Sin. -Engl. Lett. 31, 681 (2018)

[22] T. Ahmed, H.X. Jiang, W. Li, J.Z. Zhao, Acta Metall. Sin. -Engl. Lett. 31, 842 (2018)

[23] A.K. Dahle, L. Arnberg, Acta Mater. 45, 547 (1997)
[24] E. Liotti, A. Lui, R. Vincent, S. Kumar, Z. Guo, T. Connolley, I.P. Dolbnya, M. Hart, L. Arnberg, R.H. Mathiesen, P.S. Granta, Acta Mater. 70, 228 (2014)

[25] J. Zhao, J.H. Yu, K. Han, H.G. Zhong, R.X. Li, Q.J. Zhai, Acta Metall. Sin. -Engl. Lett. 31, 1334 (2018)

[26] C. Vivès, JOM-e 50, 1 (1998)

[27] R.G. Guan, D. Tie, Acta Metall. Sin. -Engl. Lett. 30, 409 (2017)

[28] F.Y. Wang, X.J. Wang, W. Sun, Y. Fu, J.Z. Cui, Acta Metall. Sin. -Engl. Lett. 33, 338 (2020)

[29] T. Campanella, C. Charbon, M. Rappaz, Metall. Mater. Trans. A 10, 3201 (2004)

[30] M.J. Bermingham, D.H. StJohn, J. Krynen, S. Tedman-Jones, M.S. Dargusch, Acta Mater. 168, 261 (2019)

[31] D. Räbiger, Y.H. Zhang, V. Galindo, S. Franke, B. Willers, S. Eckert, Acta Mater. 79, 327 (2014) 